\title{
Tres museos: \\ Experiencias recientes
}

María Eugenia Yllia Miranda

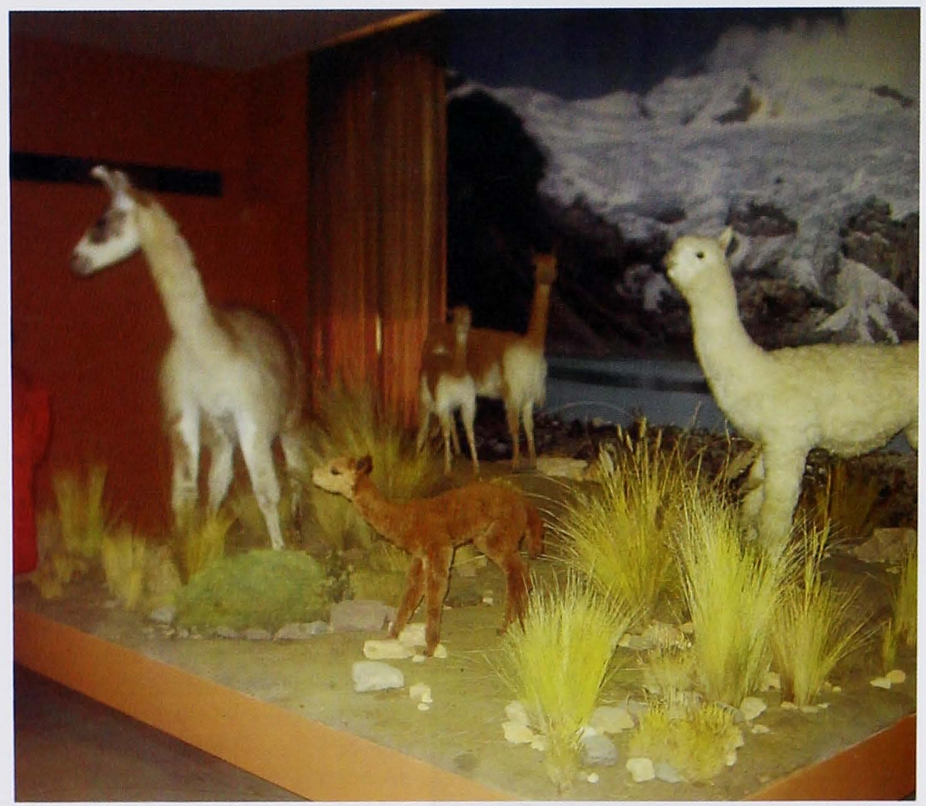

REINAUGURACIÓN DEL MUSEO SALESIANO "VICENTE RASSETO" DE HUANCAYO, JUNÍN

En abril del presente año y después de un largo periodo de remodelación iniciado en noviembre del 2002, el Museo Salesiano de Huancayo "Vicente Rasetto" abrió nuevamente sus puertas para mostrarle al público su renovada museografía.

La realización del proyecto tiene como principal gestor al Padre Jorge Atarama, Director del colegio, quien convocó a diversos especialistas entre docentes, 
arquitectos, fotógrafos, arqueólogos y alumnos de la Maestría en Museología de la URP; profesionales que desde sus propias disciplinas, brindaron asesoria en las diferentes etapas que abarcó el proceso de reestructuración.

El Museo Salesiano "Vicente Rassetto" posee una colección interdisciplinaria reunida probablemente, a partir de la llegada de la congregación italiana al Perú en 1891. Los salesianos, herederos del espíritu científico y clasificatorio de los naturalistas y viajeros del siglo XIX, se dedicaron a recolectar especímenes de flora y fauna de diversas regiones del país con la finalidad de estudiarlas. Pero es a partir de la iniciativa del P. Rasseto Bargero (1913-1998), en 1973, que el Colegio cristalizó la idea de fundar un museo escolar.

Durante la gestión del P. Rasseto la colección se incrementó considerablemente gracias a donaciones de terceras personas y, eventualmente, a las expediciones organizadas con el fin de buscar más ejemplares. Algunos años después, y siempre bajo la iniciativa del Padre Rasseto, se consiguió trasladar los objetos que poseía el antiguo Museo de la "Escuela Normal Salesiana" de Chosica (Lima), a la sede de Huancayo, logrando hacer cada vez más completa la colección.

En diferentes oportunidades se realizaron viajes fuera del país para gestionar mayores recursos que hicieran posible la implementación del museo pues el incremento de los fondos museográficos generó la necesidad de habilitar más depósitos y crear nuevos espacios expositivos. Sería en 1977 que consiguieron trasladarse a un local de mayores dimensiones que había sido utilizado como el antiguo Internado del Colegio; además, en convenio con la "Tercera Región de Educación de Junín" pudo abrir sus puertas para el público externo. Luego de la muerte del P. Rasseto en 1998, el museo fue rebautizado como Museo Salesiano "Vicente Rasseto", en reconocimiento y homenaje a su fundador y animador.

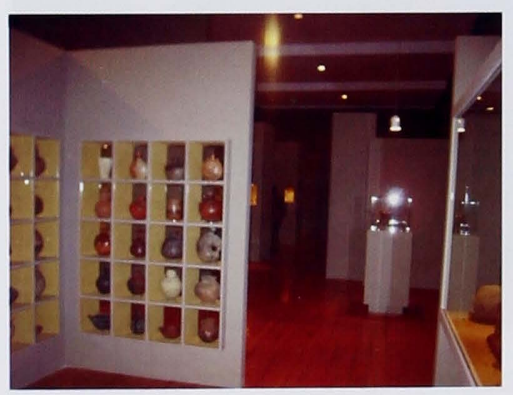

El año 2002 el P. Jorge Atarama asumió la dirección y continuó la labor del P. Rasseto y respondiendo a la demanda generada por un público que no era exclusivamente escolar, cerró temporalmente el museo para efectuar la reestructuración de sus salas de exposición y la creación de nuevos guiones museográficos. En el año 2004 pudo incorporar las colecciones del Museo Salesiano de Arequipa que, junto a otras donaciones de importantes benefactores (como las del P. Jaroslav Soukup, del Dr. David Motta y la de Norka Mora Menéndez), convirtieron este museo en uno de los más importantes de la región, tanto por la naturaleza interdisciplinaria de sus colecciones, como por ser uno de los más completos en el área de Historia Natural: sus salas y depósitos albergan actualmente un total de 1789 piezas arqueológicas, 4730 especies de la fauna nacional, 1451 especies de la fauna extranjera y 1494 monedas nacionales y extranjeras. 
Quienes conocieron el antiguo museo pueden constatar el significativo cambio que presenta su nueva museografia organizada en cuatro áreas, siendo la de Historia Natural la que destaca por el esmerado cuidado y minuciosidad con que se han realizado los detalles de cada uno de los aproximadamente cincuenta dioramas que recrean el hábitat natural de siete de las ocho ecoregiones naturales que posee nuestro país: la Costa Norte Árida, con sus manglares, bosques secos, lobos marinos, aves guaneras; los Fondos Marinos de la Corriente Fría del Mar Peruano; la Serranía Esteparia, con osos y aves rapaces; la Puna Pajonal, con venados, lagunas y totorales, vizcachas y

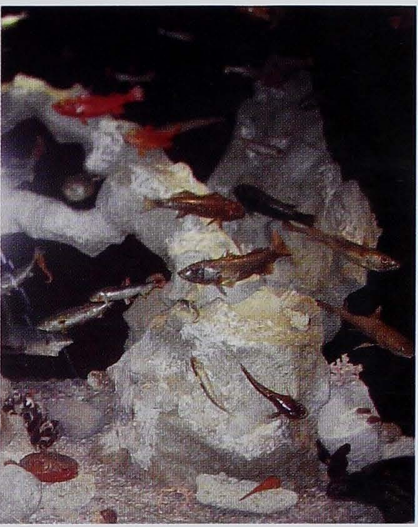
zorros y, finalmente, la Selva Alta y la Selva Baja, representadas por la diversidad de su fauna: osos hormigueros, tucanes crespos, chosnas, boas arcoiris, pájaros tornasoles, pájaros relojeros, etc.

El diseño de las salas fue desarrollado por el Arq ${ }^{\circ}$ Juan Velarde y los dioramas trabajados por un equipo integrado por la Arq⿳a Maria Orihuela Paúcar, el taxidermista Armando Carrasco Coronado, el fotógrafo Julio Angulo Delgado y un nutrido grupo de colaboradores, entre los que destacan las señoritas Carmen Marticorena Cosme y Myriam Miranda Guzmán, quienes asumieron con paciencia e ingenio la difícil tarea que implica la exhibición de animales disecados, modalidad característica de los antiguos museos de ciencias naturales, a los que con técnicas innovadoras le devolvieron su apariencia natural. Un detalle por destacar es que se trajeron exclusivamente para esta exposición especies vegetales de cada ecosistema, de modo que casi el $90 \%$ del material es natural (troncos, ramas, hojas, tierra, humus, etc.) previamente desecado y procesado mientras que el $10 \%$ está realizado mediante la maquetería y el modelismo, con los que se pudo replicar las diferentes texturas físicas propias del hábitat representado. Para dotar de realismo al diorama se utilizaron como fondo fotografias tomadas en el mismo hábitat'.

Encontramos además una nueva exhibición de material entomológico del Perú y del mundo, así como una de material arqueológico, y otra sección dedicada al textil precolombino, para cuya realización fue necesaria la presencia de los arqueólogos Pavel Leiva García y Judith Galicia Flores, quienes se encargaron del guión museográfico.

Para culminar esta nota expresamos nuestras felicitaciones al Padre Jorge Atarama y su equipo por el esmerado trabajo realizado, y lo alentamos a continuar con la labor que, como él mismo dijo durante la ceremonia inaugural -a la cual asistimos-, recién ha comenzado.

Información concedida por la Arquitecta María Orihuela Paúcar a quien agradecemos desde aquí su importante ayuda para la elaboración de esta nota. 


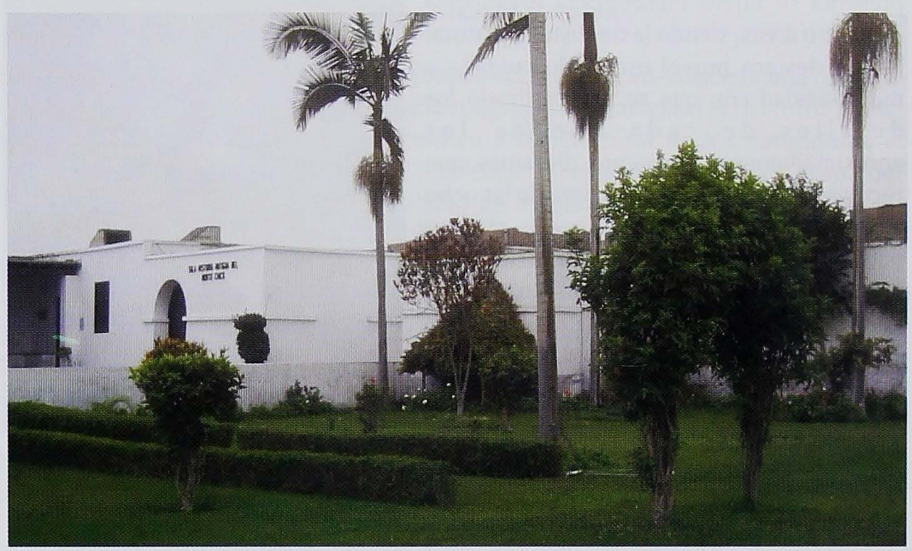

A inicios del 2005 el Museo Bolivariano de Pativilca en Barranca (Lima), inauguró la Sala Arqueológica Historia Antigua del Norte Chico, creada por el Proyecto Arqueológico del Norte Chico que financia The Field Museum (USA) y que está a cargo de un equipo de arqueólogos peruanos y estadounidenses que trabajan en esta zona desde hace algunos años. La sala construida especialmente para este fin se ha incorporado a la exhibición del Museo Bolivariano de Pativilca que ocupa la casona que habitó el libertador Simón Bolívar en su estadía en esa ciudad, entre 1823 y 1824 , en plena campaña independentista. Este edificio fue declarado monumento histórico en 1924 y convertido en museo en 1973, fecha en la que abrió sus puertas como Museo Bolivariano de Pativilca, exhibiendo fotografías y reproducciones de retratos del libertador y otros personajes; así como documentos históricos y algunos muebles de época que fueron proporcionados por el Museo Nacional de Arqueología y Antropología, los que se mantienen hasta la actualidad.

Pativilca, es una ciudad de gran importancia para la historia del Perú. Su ubicación

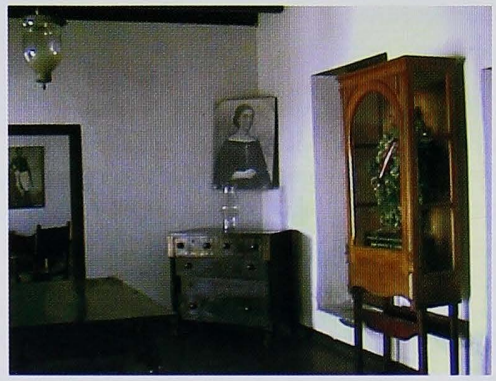
geográfica entre las ciudades de Trujilo y Lima determinó que Bolívar la eligiera como lugar estratégico para establecer su cuartel general en 1823, desde donde tomó trascendentales decisiones que definieron la independencia del Perú. En una de las Salas del museo se recuerda la anécdota que refiere que fue al pie de una palmera ubicada en el jardín trasero de la casa, donde el libertador, que se encontraba enfermo, pronunció la frase iA 
triunfar!, como conjuro por la funesta noticia del rendimiento de la guarnición del Callao ante las filas realistas.

Desde el año 2001, dos de sus salas albergan la exposición Bolívar Periodista, realizada por la empresa Editora Perú, que muestra la poco conocida faceta del libertador como hombre de prensa y fundador del diario más antiguo de Latinoamérica. En ella se puede apreciar el primer editorial de El Peruano firmado por Bolívar, la matriz de plomo, y un facsimilar del primer ejemplar publicado en 1825. La exposición se complementa mostrando la historia gráfica de la imprenta, las maquinarias y las herramientas que el proceso requiere ${ }^{2}$.

\section{LA SALA HISTORIAANTIGUA DEL NORTE CHICO}

La exposición Historia Antigua del Norte Chico está compuesta por dos Salas que organizan didácticamente la muestra y que tienen como objetivo dar a conocer los importantes hallazgos arqueológicos realizados en los últimos años que revelan parte del complejo desarrollo que alcanzaron los pueblos del Pre-cerámico Tardío (aprox. 3000 a 1800 a.c.), los cuales ocuparon los valles de Huaura, Supe (sitio arqueológico de Caral), Pativilca, y Fortaleza, conocidos comúnmente como Norte Chico. Estas edificaciones compartieron un patrón arquitectónico caracterizado por la presencia de pirámides truncas y plazas circulares escalonadas. Esta nueva información ha obligado a los científicos a reformular las hipótesis sobre el surgimiento de la civilización de los Andes Centrales, originando diversas polémicas.

La primera sala de la exposición presenta una introducción general al pasado prehispánico del Norte chico desde el Pre-cerámico Tardío hasta el Intermedio Tardío. Para ello se exhiben varias vitrinas con materiales de diversas procedencias como artefactos líticos, textiles y gasas, tallas en madera, etc. En la segunda sala se exhiben dos maquetas que representan las características arquitectónicas de los asentamientos de los Valles de Fortaleza y Pativilca.

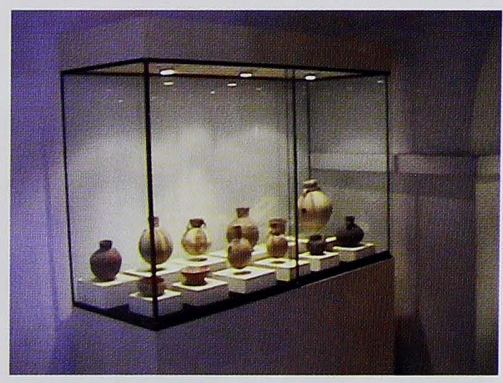

Una de las piezas más importantes de esta sala es el fragmento de calabaza que lleva pirograbado un personaje antropomorfo con dos báculos, cuya antigiiedad según el método C-14 es de 2250 años a.C. ${ }^{3}$, revelando la expresión más temprana del pensamiento religioso del hombre andino.

En otra de las vitrinas se observan muestras botánicas encontradas en las excavaciones y que son una fuente de información para la construcción de la historia

Es importante mencionar que se trata de una exposición muy didáctica que Editora Perú ha realizado y que se encuentran paralelamente en las ciudades de Piura, Arequipa, Ayacucho y en Pueblo Libre, Lima. Actualmente la veracidad de esta información es un tema de debate entre los especialistas. 
económica temprana del valle. Todas estas investigaciones, junto a otras igualmente importantes, como las desarrolladas en Caral, han dado nuevas luces sobre la trascendencia del Precerámico Tardío y su desarrollo en la zona.

\section{CONSIDERACIONES}

La creación de una sala permanente es un paso importante, pero requiere de un asesoramiento que permita alcanzar sus objetivos. Consideramos que deben corregirse ciertos aspectos. Por ejemplo, el museo no cuenta con un organigrama elemental, ni con el personal calificado que lo pueda administrar. Desafortunadamente hemos constatado que su horario de atención, similar a la de cualquier oficina del municipio, es restringido; situación agravada con su cierre los fines de semana. Esta, entre otras circunstancias, ocasiona que, a pesar de los descubrimientos arqueológicos recientes que han atraído la atención de científicos e investigadores, los pobladores de la zona, en especial los jóvenes, desconozcan la importancia que esto implica ${ }^{4}$.

Consideramos que el Museo Bolivariano de Pativilca es un lugar privilegiado que reúne todas las condiciones para convertirse en un espacio que sirva de puente entre el pasado prehispánico, el pasado histórico y el presente, y que en el futuro podría convertirse en dinamizador de la cultura local. Para ello se debe no sólo promover una gestión que supere las trabas burocráticas sino una mejora integral de sus servicios que lo habilite como instrumento generador de recursos que puedan ser reinvertidos a fin asegurar su sostenibilidad y el desarrollo del entorno ${ }^{5}$.

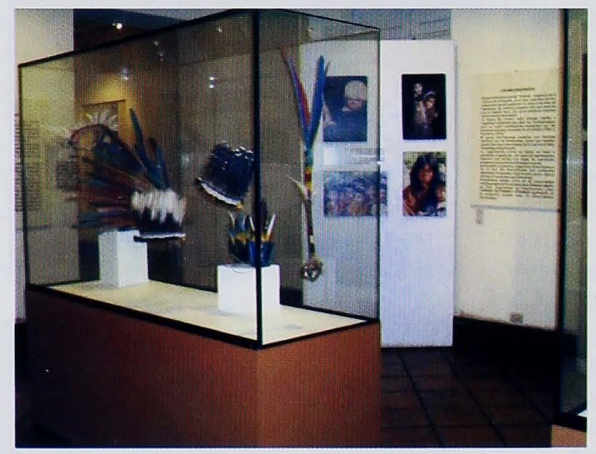

EL MUSEO ETNOGRÁFICO DEL CENTRO CULTURAL PÍO AZA - LIMA

El reconocimiento y respeto de otros sistemas culturales constituye, en el actual y vertiginoso contexto globalizado, una necesaria y oportuna manera de comprender nuestro país; premisa que resulta vital para emprender cualquier proyecto como nación, que involucre a todos los grupos locales y regionales. Esta visión es entendida y puesta en práctica por el Museo Etnográfico del Centro Cultural Pío Aza de la orden dominica, que desde su fundación en julio del 2003 , se ha propuesto difundir en el contexto

\footnotetext{
Existe una gran diferencia entre la desactualizada museografia de la casona y la nueva Sala Arqueológica. Información brindada gentilmente por el profesor Manuel Cornejo Balabarca, amplio conocedor de la historia de Pativilca, a quien agradecemos infinitamente su colaboración.
} 
capitalino la riqueza cultural de los pueblos amazónicos del Sur Oriente Peruano, de los departamentos de Madre de Dios, Cusco y Ucayali. En este museo, ubicado en pleno centro histórico de Lima, podemos encontrar una gran diversidad de objetos que caracterizan a las culturas amazónicas y constituyen el correlato material de su vida espiritual y mitológica ${ }^{6}$.

Desde su llegada al Perú en 1902, los dominicos tuvieron especial interés en conservar y difundir la cultura material de los grupos étnicos de la región. En la década de los cuarenta fundaron el Museo de la Granja Escuela de Quillabamba - Cusco, que funcionó durante dos décadas, fecha en que

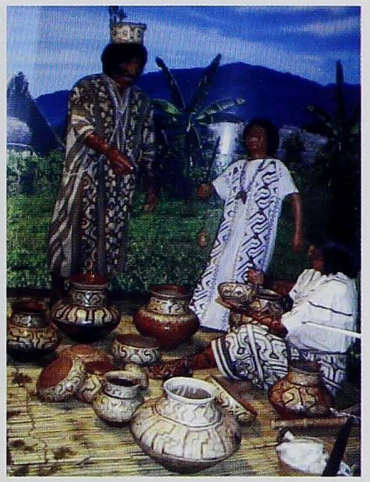
fundaron su nuevo Museo Etnográfico en el Convento Santa Rosa de la ciudad de Lima, que dejó de funcionar en 1988, luego de la reorganización urbanística.

La presencia constante de los dominicos en esa zona ha hecho posible que el museo posea en la actualidad un total de 900 piezas, buena parte de las cuales datan de hace varias décadas y provienen de las etnias Harakmbut y Esse Eja de Madre de Dios; Matsigenka, Asháninka y Yine de la familia Arawak del Alto Ucayali; Amahuaca, Sharanahua, Yaminahua del río Purús. Además de los Nahua de los ríos Mishaua y Manu; y de los Nantis-Kugapaporis de los ríos Camisea, Timpia y Ticumpinía. etc.; cuya expresión material se encuentra en la exposición permanente y en los depósitos.

La nueva exposición desarrollada por el experimentado museógrafo Rodolfo Vera, tiene como objetivo principal introducir al visitante, en especial al público escolar, en el conocimiento de la mitología, cultura social y material de las etnias amazónicas. Una sala con fotografías y planos de la región muestra al visitante las actividades realizadas por los primeros misioneros, entre los que destaca el Padre español José Pío Aza (1865-1938), fundador de las Misiones del Vicariato Apostólico de Santo Domingo en Urubamba y Madre de Dios. El Padre Aza exploró en la primera década del siglo XX los grandes ríos de Madre de Dios, que hasta entonces no existían en la cartografía oficial. Además de sus aportaciones en el campo de la geografía y etnología, hay que destacar su diccionario y gramática de la lengua matsigenka, que con el título "Estudio de la lengua machiguenga" fue publicado en Lima en 1932.

En esta misma sala observamos los mapas de las misiones de San José Koribeni en Cusco, San Miguel o Shintuya en Madre de Dios, el Rosario o Sepahua en el Ucayali, San Pedro o Timpia y la Inmaculada de Quillabamba estas últimas en el Cusco . La sala se complementa con un diorama de tamaño natural del Jefe Piro de Sepahua, Manuel Chamiro, vestido con la cushma o atuendo tradicional y ataviado con una corona de fibra vegetal y coloridas plumas, elementos que indican su distinción y rango.

Agradecemos a Rafael Alonso del Centro Cultural Pío Aza, que gentilmente nos dio las facilidades para visitar el Museo y a Manuel Cornejo Chaparro por su ayuda en la elaboración de esta nota.PA. 


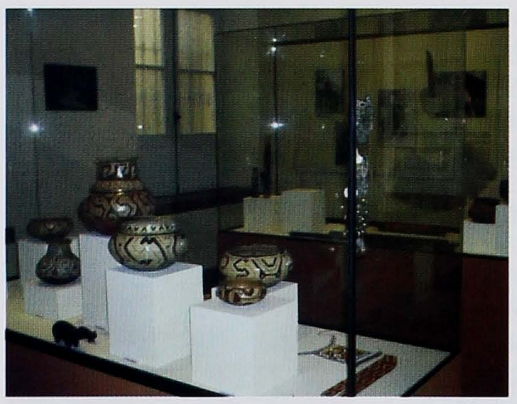

En las siguientes salas observamos objetos rituales y utilitarios de los Matsigenka, Harakmbut y Esse Eja, muchos de los cuales han quedado en el olvido por el paso de la modernidad. Vemos una vitrina dedicada a las máscaras confeccionadas con calabazas y decoradas con huesos, incisiones, pigmentos naturales y otros materiales de variada procedencia. En otra vitrina están los objetos elaborados en fibra vegetal entre los que sobresalen un bolso de llanchama o corteza de árbol procesada cuyo uso fue extensivo a varios grupos de la amazonía; un hacha de piedra con mango de resina de copal, instrumentos para generar fuego, peines, collares y otros objetos del arreglo personal. En este grupo sobresalen los inhaladores de rapé (planta que produce efectos enteógenos en los individuos) y el cargador de bebés Kushipe y opchin o fabricado en fibras vegetales tejidas y utilizadas por las madres Harakmbut para transportar a sus hijos.

También podemos apreciar las cofias y tocados de uso ceremonial político y religioso. Hay que señalar que las coronas de plumas adquieren su importancia según la edad y el status social de sus portadores. Su vistosidad es producto del uso de diferentes tipos de aves y su uso magistral en la combinación que denota su cabal conocimiento del entorno.

Un detallado diorama nos permite ingresar al interior de una casa matsigenka y observar cómo se desarrolla la vida cotidiana de los indígenas. En él observamos la cocina, las vasijas de cerámica y los distintos utensilios utilizados por las mujeres en sus actividades domésticas, así como la dieta alimenticia basada en yuca, plátano y pescado. El extremo cuidado de los detalles responde a la supervisión de un profesor matsigenka.

Además de esta muestra etnográfica, el Centro Cultural Pío Aza desarrolla importantes actividades paralelas como exposiciones temporales, conferencias; asimismo, ofrece los servicios de su biblioteca.

Esa antigua y polémica frase de Valdelomar "Lima es el Perú" cobra ahora un nuevo sentido: basta darse una vuelta por el centro de Lima y conocer un poco de toda la riqueza que ofrece nuestra Amazonía. 